\title{
Formação docente, tecnologia educacional e Educação Ambiental pós-pandemia da Covid-19
}

\section{Teacher training, educational technology, and Environmental Education post-Pandemic of Covid-19}

\section{Formación de profesores, tecnología educativa y educación ambiental post-pandémica de Covid-19}

\author{
Andrea Vieira' \\ Célia Tanajura ${ }^{2}$ \\ Diogo Souza ${ }^{3}$
}

\begin{abstract}
Resumo
O presente artigo objetiva refletir sobre o contexto político e legal da formação de professores para o Ensino de Ciências no Brasil e o papel da Educação Ambiental durante e após a pandemia da Covid-19, quando do retorno dos estudantes das redes públicas de ensino às atividades escolares, levando em consideração o uso da tecnologia educacional como possibilidade de uma interlocução transformadora na vida escolar. O estudo aqui apresentado caracteriza-se como um exercício teórico e adotou, como metodologia para a produção de dados estudos bibliográficos e análise de documentos. Como resultados encontrados restou consolidada a necessidade de que as aprendizagens alcançadas por estudantes e professores durante a quarentena devem ser valorizadas, especialmente em processo de formação de professores para o Ensino de Ciências e que os saberes aprendidos em Educação Ambiental são fundamentais para a convivência de estudantes e professores nas escolas, quando do retorno às atividades escolares.
\end{abstract}

Palavras Chaves: Pandemia da Covid-19. Formação de professores. Ensino de Ciências. Educação Ambiental.

\section{Abstract}

This article aims to reflect on the political and legal context of teacher training for Science Teaching in Brazil and the role of Environmental Education during and after the Covid-19 pandemic, when students return from public school networks to school activities, taking into consideration the use of educational technology as a possibility of a transforming interlocution in school life. The study presented here is characterized as a theoretical exercise and adopted, as methodology to produce data, bibliographic studies and document analysis. As results found, it remains consolidated the need that the learning achieved by students and teachers during the quarantine should be valued, especially in the process of training teachers for Science Teaching and that the knowledge learned in Environmental Education is fundamental for the coexistence of students and teachers in schools, when returning to school activities.

Keywords: Pandemic of Covid-19. Teacher training. Teaching of Sciences. Environmental Education.

' Coordenação de Aperfeiçoamento de Pessoal de Nível Superior, Brasília, DF, Brasil.

2 Universidade Estadual da Bahia, Salvador, BA, Brasil.

${ }^{3}$ Universidade Federal do Rio Grande do Sul, Porto Alegre, RS, Brasil 


\section{Resumen}

El presente artículo tiene por objeto reflexionar sobre el contexto político y jurídico de la formación de docentes para la Enseñanza de las Ciencias en Brasil y el papel de la Educación Ambiental durante y después de la pandemia de la Covid-19, teniendo en cuenta el uso de la tecnología como posibilidad de una interlocución transformadora en la vida escolar. El estudio que aquí se presenta se caracteriza por ser un ejercicio teórico y ha adoptado, como metodología para la producción de datos, estudios bibliográficos y análisis de documentos. Como resultados encontrados la necesidad de que los aprendizajes alcanzados por estudiantes y docentes durante la cuarentena deben ser valorizados, especialmente en el proceso de formación de docentes para la Enseñanza de las Ciencias y que los conocimientos aprendidos en Educación Ambiental son fundamentales para la convivencia de estudiantes y docentes en las escuelas, al regresar a las actividades escolares.

Palabras Clave: Pandemia de Covid-19. Formación de profesores. Enseñanza de las ciencias. Educación Ambiental

\section{Introdução}

A educação no Brasil vem apresentando melhoras nos indicadores oficiais e os instrumentos normativos que se dispõe a "moldar" esse processo (Lei de Diretrizes e Bases (LDB N 9.394 / 1996), o Fundo de Manutenção e Desenvolvimento da Educação Básica e de Valorização dos Profissionais de Educação (Fundeb) e os outros que regem a organização e funcionamento educação básica no país) se consolidam como construção histórica de um novo modelo de educação forjado ao longo das últimas décadas. Contudo, ainda são muitas as questões a serem resolvidas para que a educação no Brasil avance com a oferta de um ensino de qualidade.

O ano de 2020, iniciou-se com informações de que no mundo circulava um novo vírus extremamente contagioso, causador da doença do coronavírus (a Covid-19)4. Com letalidade relativamente baixa, os casos graves que atingem as pessoas acometidas pela doença são suficientes para colapsar a melhor infraestrutura hospitalar existente no mundo contemporâneo. Em decorrência da propagação acelerada, não tardou para que o flagelo atingisse o patamar de pandemia e, consequentemente, medidas sanitárias urgentes, como fechamento de escolas, comércio e fronteiras, foram tomadas em todo o mundo com o intuito de aliviar a pressão sobre os sistemas de saúde e preservar vidas.

De acordo com a Organização das Nações Unidas para a Educação, a Ciência e a Cultura (UNESCO), agência especializada das Nações Unidas (ONU), o período de quarentena deflagrado para impedir a proliferação da Covid-19, deu início à maior interrupção de oferta presencial da educação da história mundial, podendo levar a uma "catástrofe geracional" no aprendizado. Assim, no início de abril de 2020, 91,4\% da população de estudantes do mundo foram afetados pelo fechamento das escolas em 192

${ }^{4}$ Braga e Módolo (2020) Disponível em: https://jornal.usp.br/artigos/covid-temgenero/\#: :text=Dessa\%20forma\%2C\%20apregoa\%20a\%20Acad\%C3\%A9mie,governo\%20chin\%C3\%A As\%20no\%20final\%20de 
países, ou seja, eram 1,57 bilhão de estudantes fora do ambiente escolar (UNESCO, 2020).

O fechamento das escolas representou enormes desafios para governos de todo o mundo, especialmente, para os países em situação de grandes extensões e desigualdades sociais e econômicas, como o Brasil, expôs e aprofundou as fragilidades a que são cotidianamente submetidos crianças e adolescentes em situação de vulnerabilidade e risco social e pessoal. Nem mesmo a Declaração Universal dos Direitos Humanos5 (1948) ou a Constituição Federal do Brasil6 (1988), instrumentos que pretendem garantir a educação como direito de todos, promovida e incentivada de forma contínua, pode apoiar essa parcela da população no auge da crise.

Com vistas a superar as dificuldades inerentes a esse período, soluções e ferramentas as mais diversas emergiram, induzindo as instituições de ensino a se reorganizarem em função do exercício docente e de aprendizagem do estudante na modalidade a distância. Mesmo com o empenho das referidas instituições, as desigualdades sociais, em virtude de obstáculos ao acesso digital, tornaram-se mais evidentes expondo a fragilidade do acesso à educação a quem não dispõe dos mesmos meios de consumo digital e conhecimento das tecnologias de informação e comunicação (TICs) e expôs os mais desfavorecidos ao risco de maior defasagem no processo de aprendizagem. Além da performance prejudicada, ainda existe a grande possibilidade de evasão escolar gerada pelo desestímulo ao aprendizado frente às dificuldades deste novo modelo de "aprender/ensinar".

Durante anos, especialistas no ensino debatem uma série de mudanças nas metodologias que compõem a forma do ensino e aprendizado atualmente em prática, mesmo assim, o sistema brasileiro de educação, não estava preparado para a magnitude da situação. O Instituto de Pesquisa Econômica Aplicada (IPEA) publicou um relatório sobre o acesso Domiciliar à Internet e Ensino Remoto Durante a Pandemia (IPEA, 2020), no qual é possível compreender o perfil dos discentes sem acesso domiciliar à internet de qualidade, o que reforça o aspecto da desigualdade social que assola o Brasil, conforme apresentado na Tabela 1.

\footnotetext{
${ }^{5}$ Acessível em:https://nacoesunidas.org/direitoshumanos/declaracao/

${ }^{6}$ Acessível em: http://www.planalto.gov.br/ccivil_03/constituicao/constituicao.htm
} 
Tabela 1 - Estudantes matriculados nas instituições públicas de ensino sem acesso domiciliar à internet de qualidade, em 2018, por gênero, cor/raça níveis e etapas de escolarização (em \%)

\begin{tabular}{|c|c|c|c|c|}
\hline \multirow{4}{*}{$\begin{array}{c}\text { Nível e etapa de } \\
\text { escolarização }\end{array}$} & \multicolumn{4}{|c|}{ Gênero } \\
\hline & \multicolumn{2}{|c|}{ Mulheres } & \multicolumn{2}{|c|}{ Homens } \\
\hline & \multicolumn{4}{|c|}{ Cor/Raça } \\
\hline & $\begin{array}{l}\text { Negras e } \\
\text { Indígenas }\end{array}$ & $\begin{array}{l}\text { Brancas e } \\
\text { Amarelas }\end{array}$ & $\begin{array}{l}\text { Negros e } \\
\text { Indígenas }\end{array}$ & $\begin{array}{l}\text { Brancos e } \\
\text { Amarelos }\end{array}$ \\
\hline Pré-escola & 37 & 14 & 37 & 12 \\
\hline Ensino fundamental & 35 & 11 & 41 & 13 \\
\hline Ensino médio & 38 & 12 & 39 & 11 \\
\hline $\begin{array}{l}\text { Graduação e pós- } \\
\text { graduação }\end{array}$ & 36 & 20 & 33 & 11 \\
\hline
\end{tabular}

Fonte: Adaptado pelos autores, a partir da Nota Técnica $N^{\circ} 88$ (Acesso Domiciliar à Internet Ensino Remoto Durante a Pandemia) (IPEA, 2020)

A pandemia da Covid-19 traz questões que precisam de reflexão no âmbito da educação, tais quais 0 acesso às ferramentas tecnológicas disponibilizadas, a infraestrutura necessária para viabilizar esse processo, a preparação dos professores para utilizar as ferramentas de forma que o processo de aprendizagem seja o menos prejudicado possível. Na seara voltada para a realidade dos professores, surgem ainda questões como as políticas de formação de professores, tanto inicial quanto continuada, que pedem um olhar cuidadoso do Estado, implicado com os novos desafios impostos na contemporaneidade.

No que concerne ao Ensino de Ciências, notadamente, no contexto referente à Educação Ambiental, torna-se necessário compreendê-la como ferramenta poderosa para o enfrentamento aos desafios climáticos, políticos e sociais, como posto pelo primeiro artigo da Política Nacional de Educação Ambiental, ou seja, "[...] o indivíduo e a coletividade constroem valores sociais, conhecimentos, habilidades, atitudes e competências voltadas para a conservação do meio ambiente, bem de uso comum do povo, essencial à sadia qualidade de vida e sua sustentabilidade". (BRASIL, 1999)

As diferentes dimensões que envolvem a pandemia da Covid-19 e o uso intensivo de tecnologias educacionais implicam diretamente em refletir sobre a formação de professores no Brasil, considerando a Base Nacional de Formação Docente (que não incluía a pandemia, a qual alterou a rotina escolar e profissional dos docentes) e, neste estudo, o Ensino de Ciências, com o foco na Educação Ambiental.

Importante salientar que o Brasil, antes da crise causada pela Covid-19, se encontrava em um cenário econômico adverso que foi agravado pela pandemia, que 
impactou na paralisação das atividades da indústria e do comércio e na desvalorização da moeda nacional frente à norte-americana. Além disso, o agravamento da crise sanitária promoveu um desgaste político-institucional significativo, trazendo insegurança e incerteza para grande parte da população brasileira, em decorrência, principalmente, da divulgação de fake news e do crescimento de movimentos anticiência, protagonizados por parcelas conservadoras da sociedade brasileira (HENRIQUES; VASCONCELOS, 2020).

Neste contexto, o Ensino de Ciências e a Educação Ambiental encontram o lócus perfeito para ratificar a sua relevância e a conscientização de como podemos ser impactados por situações que fogem ao controle de qualquer governo e devem receber atenção de grupos de pesquisa e recursos financeiros para viabilizar os estudos. Assim, este artigo visa refletir sobre o contexto político e legal da formação de professores para o Ensino de Ciências no Brasil e o papel da Educação Ambiental durante e após a pandemia da Covid-19, quando do retorno dos estudantes das redes públicas de ensino às atividades escolares, levando em consideração o uso da tecnologia educacional como possibilidade de uma interlocução transformadora na vida escolar

\section{A Formação de Professores e Tecnologia Educacional em tempos de Pandemia da Covid-19}

Realizar reflexões sobre a temática que envolve a formação de professores, o ensino de Ciências, em especial a Educação Ambiental, e o aparato tecnológico que está sendo mobilizado pelas escolas de educação básica durante a pandemia, não é uma tarefa fácil. No entanto, o momento vivido pelo planeta impulsiona a aceitação de novos desafios e permite um olhar holístico, concatenando em diferentes dimensões. Assim sendo, tornase premente considerar novas oportunidades para realizar o ensino de Ciências à luz de novos planos de ações para as pessoas, para o planeta e para a prosperidade, tais como a agenda 20307 para o Desenvolvimento Sustentável. Esta é uma opção que possibilita extrair e aproveitar o melhor de um momento de ruptura em relação ao modelo até aqui vigente na rotina escolar, introduzindo novos elementos voltados para o desenvolvimento global, que fortaleça a Educação Ambiental, o desenvolvimento sustentável, a economia e a sociedade como um todo.

Os obstáculos e dificuldades enfrentados pela educação básica no Brasil têm relação com a desigualdade social e ao não acesso a vários dos direitos constitucionais (ZANCAN RODRIGUES; PEREIRA; MOHR, 2020). Estas questões tornaram-se mais evidentes durante a pandemia da Covid-19. Porém, quando se observa o contexto político e legal que regula a formação de professores no Brasil e o seu distanciamento da realidade hoje demandada às escolas (vinculadas aos impactos da pandemia e dela decorrentes), percebe-se que se faz necessário formular ações com o objetivo de mitigar as perdas na aprendizagem dos estudantes.

A formação de professores, principalmente a formação continuada, pode exercer

7https://www.gov.br/secretariadegoverno/pt-br/assuntos/secretaria-especial-de-articulacaosocial/capa/noticias/o-governo-brasileiro-e-a-agenda-2030-1 
influência positiva sobre o trabalho pedagógico do professor e, de uma forma geral, sobre novas formas de produzir o seu trabalho, principalmente quando se trata da utilização de ferramentas tecnológicas de hard e de software dos mais diferentes formatos e matizes. Cabe salientar, entretanto, que não se espera que apenas o professor seja o único responsável pelo sucesso e aprendizagens dos seus estudantes. O que se espera é que o professor seja preparado adequadamente para enfrentar diferentes cenários com criatividade e motivação. Todavia, tão somente uma política de valorização dos profissionais da educação (de amplo escopo), que envolva toda a comunidade escolar (docentes e não-docentes) pode propiciar a implementação de políticas para a educação básica em que os esforços implementados não restem comprometidos.

A formação de professores no Brasil, segundo Gatti (2010), carece de uma verdadeira revolução nas estruturas institucionais formativas e nos currículos da formação, haja vista a necessidade de se implementar processos formativos que respeitem as necessidades da prática pedagógica docente, o contexto escolar e as demandas advindas da realidade de cada comunidade escolar, reveladas, portanto, no currículo escolar e nos desafios a ele apresentados.

A formação do professor se constitui como um dos elementos mais importantes no processo de profissionalização desse profissional da educação. Em conjunto com a construção do seu percurso profissional (carreira e remuneração), a prática pedagógica cotidiana e as experiências que nela constrói, a formação do professor impacta diretamente no trabalho pedagógico que ele realiza e nos resultados de aprendizagens dos seus estudantes. Nos últimos dez anos, o Brasil produziu uma série de instrumentos legais que impactam diretamente a formação de professores. Contudo, a situação atual do processo de formação de professores (inicial e continuada), ainda permanece sem alterações relevantes que tenham revelado mudanças importantes no "chão da escola", em parte, ainda de acordo com Gatti (2010), tal situação ocorre em consequência do alto nível de fragmentação que perpassa os programas de formação.

O Quadro 1 apresenta a legislação que organiza e regulamenta a formação de professores da educação básica no Brasil, por data de publicação e matéria de que trata (2010-2019). 
Quadro 1 - Legislação que organiza e regulamenta a formação de professores da educação básica no Brasil, por data de publicação e matéria de que trata (2010-2019)

\begin{tabular}{|c|c|c|}
\hline INSTRUMENTO & DATA PUBLICAÇÃO & MATÉRIA \\
\hline Portaria MEC $\mathrm{n}^{\circ} 1.087$ & 10 de agosto de 2011 & $\begin{array}{l}\text { Comitê Gestor da Política Nacional de } \\
\text { Formação Inicial e Continuada de } \\
\text { Profissionais da Educação Básica }\end{array}$ \\
\hline Portaria MEC $\mathrm{n}^{\circ} 1.328$ & $\begin{array}{l}23 \text { de setembro de } \\
2011\end{array}$ & $\begin{array}{c}\text { Rede Nacional de Formação Continuada } \\
\text { dos Profissionais do Magistério da } \\
\text { Educação Básica Pública }\end{array}$ \\
\hline Lei $n^{\circ} 13.005$ & 25 de junho de 2014 & $\begin{array}{l}\text { Plano Nacional de Educação (PNE) e dá } \\
\text { outras providências (PNE 2014-2024) }\end{array}$ \\
\hline Decreto $\mathrm{n}^{\circ} 8.752$ & 9 de maio de 2016 & $\begin{array}{l}\text { Política Nacional de Formação dos } \\
\text { Profissionais da Educação Básica }\end{array}$ \\
\hline Lei $n^{\circ} 13.415$ & $\begin{array}{l}16 \text { de fevereiro de } \\
2017\end{array}$ & $\begin{array}{l}\text { Política de Fomento à Implementação } \\
\text { de Escolas de Ensino Médio em Tempo } \\
\text { Integral, e dá outras providências }\end{array}$ \\
\hline Resolução CNE/CP n ${ }^{\circ} 2$ & $\begin{array}{l}22 \text { de dezembro de } \\
2017\end{array}$ & $\begin{array}{l}\text { Base Nacional Comum Curricular } \\
\text { (BNCC) }\end{array}$ \\
\hline Resolução CNE/CP n ${ }^{\circ} 4$ & $\begin{array}{l}17 \text { de dezembro de } \\
2018\end{array}$ & $\begin{array}{l}\text { Base Nacional Comum Curricular na } \\
\text { Etapa do Ensino Médio (BNCC-EM) }\end{array}$ \\
\hline $\begin{array}{c}\text { Resolução CNE/CEB } n^{\circ} \\
3\end{array}$ & $\begin{array}{l}21 \text { de novembro de } \\
2018\end{array}$ & $\begin{array}{c}\text { Diretrizes Curriculares Nacionais para o } \\
\text { Ensino Médio }\end{array}$ \\
\hline Resolução CNE/CP n ${ }^{\circ} 2$ & $\begin{array}{l}20 \text { de dezembro de } \\
2019\end{array}$ & $\begin{array}{c}\text { Diretrizes Curriculares Nacionais para a } \\
\text { Formação Inicial de Professores para a } \\
\text { Educação Básica e Base Nacional } \\
\text { Comum para a Formação Inicial de } \\
\text { Professores da Educação Básica (BNC- } \\
\text { Formação) }\end{array}$ \\
\hline
\end{tabular}

Fonte: Ministério da Educação8

Quando se fala em formação de professores é necessário mencionar as iniciativas no âmbito da Coordenação de Aperfeiçoamento de Pessoal Superior (Capes), que é responsável pela formação de professores da educação básica, a partir da publicação da Lei $n^{\circ} 11.502$, de 11 de julho de 2007. Por este dispositivo legal, a Capes se tornou o órgão

8 Acessível em: http://portal.mec.gov.br/conselho-nacional-de-educacao/atos-normativos-sumulas-pareceres-e-resolucoes 
responsável por subsidiar "[...] o Ministério da Educação na formulação de políticas e no desenvolvimento de atividades de suporte à formação de profissionais de magistério para a educação básica e superior e para o desenvolvimento científico e tecnológico do País" (BRASIL, 2007). Notadamente no âmbito da educação básica, à Capes foi atribuída a tarefa de

[...] induzir e fomentar, inclusive em regime de colaboração com os Estados, os Municípios e o Distrito Federal e exclusivamente mediante convênios com instituições de ensino superior públicas ou privadas, a formação inicial e continuada de profissionais de magistério, respeitada a liberdade acadêmica das instituições conveniadas [...] (BRASIL, 2007).

Em 2017, por meio do Decreto $n^{\circ} 8.977$, de 30 de janeiro de 2017, do governo federal, a estrutura organizacional da Capes é modificada e os objetivos da formação dos professores da educação básica, ajustados a esta nova estrutura, assim restaram estabelecidos, com a criação da Diretoria de Formação de Professores da Educação Básica:

I - fomentar a articulação e o regime de colaboração entre os sistemas de ensino da educação básica e da educação superior, inclusive da pósgraduação, para a implementação da Política Nacional de Formação de Profissionais do Magistério da Educação Básica;

II - subsidiar a formulação de políticas de formação inicial e continuada de professores da educação básica;

III - apoiar a formação de professores da educação básica, mediante concessão de bolsas e auxílios para o desenvolvimento de estudos, pesquisas, projetos inovadores, conteúdos curriculares e de material didático;

IV - apoiar a formação de professores da educação básica mediante programas de estímulo ao ingresso na carreira do magistério;

$\mathrm{V}$ - fomentar o uso das tecnologias de informação e da comunicação nos processos de formação de professores da educação básica;

VI - elaborar, juntamente com a Diretoria de Educação a Distância, a revisão anual das atividades relativas à educação básica; e

VII - presidir o Conselho Técnico Científico da Educação Básica

De acordo com (SILVA NETO et al., 2016, p. 151), as "novas competências atribuídas à Capes a partir de 2009 favoreceram o surgimento de diversas políticas voltadas para a formação de professores, tanto inicial quanto continuada", a saber:

1. Formação Inicial

(1) Programa Institucional de Bolsas de Iniciação à Docência - Pibid

(2) Plano Nacional de Formação de Professores da Educação Básica - Parfor

2. Formação Continuada 
(1) Programa de Consolidação das Licenciaturas (Prodocência)

(2) Observatório da Educação (Obeduc)

(3) Programa de Apoio a Projetos Extracurriculares: Investindo em Novos Talentos da Rede Pública para Inclusão Social e Desenvolvimento da Cultura Científica (Programa Novos Talentos)

(4) Cooperação Internacional

(5) Programa Laboratórios Interdisciplinares de Formação de Educadores (Life)

(6) Residência Docente/ Residência Pedagógica

(7) Formação dos Professores das Olimpíadas Científicas

(8) Feiras de Ciências, Mostras e Olimpíadas Científicas, dentre outros (com contribuições de SILVA NETO et al., 2016).

Dentre as diferentes ações voltadas para a formação continuada de professores no âmbito da Capes, destacam-se o Programa Institucional de Bolsas de Iniciação à Docência (Pibid) e os Programas Residência Docente/Residência Pedagógica. Criado em 2007 e implementado a partir de 2008, o Pibid foi iniciado com 3088 bolsistas, e, segundo Villas Bôas, Martins e Soares Neto (2019), em 2014 a concessão bolsas alcançou 90.254 indivíduos (estudantes, professores do ensino superior e da educação básica). Em 2014, o Pibid abrangeu 284 instituições de ensino superior, envolvendo, aproximadamente, 6.000 escolas parceiras das redes públicas municipais ou estaduais. Por meio da Portaria n. ${ }^{\circ} 206$, a Capes lançou em 21 de outubro de 2011, o Programa Residência Docente, a implantarse no Colégio Pedro II, em caráter experimental. Em anos posteriores, a iniciativa se estendeu para outras instituições, ainda de forma restrita. Entretanto, ainda que sua origem tenha se dado no âmbito da Capes, somente após a publicação do Decreto n. ${ }^{\circ}$ 8.752/2016 "a residência pedagógica e a residência docente passaram a ser consideradas ações possíveis para a Política Nacional de Formação dos Profissionais da Educação Básica" (FARIA, J. B.; DINIZ-PEREIRA, 2019). Ambas as iniciativas estão no centro das discussões sobre programas realizados em parceria com os cursos de Licenciaturas das instituições de ensino superior com o objetivo de tornar a formação inicial de professores mais robusta e próxima à realidade escolar.

Ainda, no contexto da formação de professores no Brasil, a publicação, em dezembro de 2019, da Base Nacional Comum para Formação de Professores da educação básica (BNCFP) gerou apreensão e incertezas na comunidade educacional. ZANCAN RODRIGUES, PEREIRA e MOHR (2020) fazem uma análise detalhada da proposta da BNCFP e traz dez argumentos que devem ser refletidos, principalmente quando considerado todo o arcabouço legal que hoje sustenta a educação básica do Brasil. Mesmo apresentando críticas à BNCFP, ZANCAN RODRIGUES, PEREIRA e MOHR (2020) reconhecem que, embora existam avanços, a diferença entre o que é necessário para o professor assumir a sala de aula e exercer a sua profissão em escolas de educação básica e o que é ensinado nos cursos superiores de formação de professores, ainda é grande. Para a autora (ZANCAN 
RODRIGUES; PEREIRA; MOHR, 2020), é essencial aproximar escola básica e universidade, embora não seja esta uma tarefa simples, pois demanda uma série de iniciativas que envolvem questões que estão além do processo formativo acadêmico em si, porquanto perpassa pela valorização dos profissionais envolvidos, do apoio às instituições, investimentos em salários e infraestrutura etc. Enfim, que a formação dos professores da educação básica esteja inserida na agenda política e se consolide como elemento fundamental no processo de melhoria de qualidade educacional e social dos sistemas públicos de ensino.

Para Vasconcelos (2017), mais do que informações e conceitos, é necessário que as escolas e os professores se proponham a trabalhar com atitudes, com a formação de valores, com o ensino e aprendizagem de procedimentos. Conhecimentos e atitudes, teoria e prática, elementos que devem formar um amálgama no processo de formação dos professores, mas, acima de tudo, devem revelar os anseios e as necessidades da comunidade escolar e dos profissionais docentes. Assim é que, conforme Dal-Farra e Valduga (2012):

Os processos de formação docente continuada devem ser calcados na construção coletiva decorrente do levantamento dos aspectos principais que serão incluídos na abordagem, tanto em relação aos anseios da comunidade de docentes, quanto em relação às demandas de ordem técnica vinculadas à instrumentalização dos professores no âmbito dos fundamentos teóricos subjacentes às Ciências da natureza, à matemática e às Ciências humanas (DAL-FARRA; VALDUGA, 2012, p. 406).

Nesse sentido, são grandes e diversos os desafios colocados para a formação dos professores. No contexto da pandemia da Covid-19, esses desafios foram maximizados pela necessidade de escolas, professores e sistemas públicos de ensino se reinventarem, a fim de promoverem o acesso e a conexão de estudantes aos conhecimentos escolares, em áreas mais urbanizadas ou em remotas escolas do campo, como forma de garantir o direito à educação e à aprendizagem. Em todo o mundo, as estratégias adotadas, desde que os contágios se avolumaram e medidas restritivas de convívio social foram adotadas, os estudantes e professores, afastados das escolas, passaram a se comunicar remotamente. Assim, o campo da educação se tornou o maior laboratório de trabalho remoto da humanidade, como também a maior experiência em educação mediada por tecnologia da história.

Dessa forma, pensar em um modelo de formação de professores que também absorva o potencial da tecnologia educacional, é estar ciente de que existem desafios a serem percorridos e que essa dimensão implica em uma ação integrada entre escola, profissionais, governo e sociedade, objetivando a formação de sujeitos sociais com novos conhecimentos e capacidade para utilizar, de forma consciente e planejada, as ferramentas 
pedagógicas e tecnológicas disponíveis, de maneira assimétrica, em cada escola, de acordo com os seus limites e possibilidades.

Vale destacar, aqui, que a formação de professores, no Brasil, histórica e prioritariamente esteve fundamentada em metodologias de ensino presenciais. Em muitas escolas públicas, os laboratórios de informática eram espaços destinados preferencialmente a professores das áreas de tecnologias, nos quais os estudantes eram iniciados em ferramentas tecnológicas e digitais. Entretanto, esta realidade mudou e mudou de forma muito abrupta. Com a extensão das medidas sanitárias e do período pelo qual elas se estenderam, o ano letivo se tornou completamente comprometido para os estudantes das escolas públicas que não puderam acessar alternativas tecnológicas para se conectarem com as suas escolas se os seus professores. Esta nova realidade, imposta por um novo contexto implicou na necessidade premente se deslocar o fazer pedagógico presencial para outro que privilegie metodologias de ensino mediadas por ferramentas tecnológicas, ou mesmo para metodologias híbridas de melhor qualidade e acessibilidade (PILab/UnB, 2020).

A pandemia forçosamente impôs a todos um distanciamento quase que imediato e a resposta da educação pública, com propostas efetivas para a continuidade das aulas, não foi tão rápida. A maior dificuldade residia na infraestrutura necessária para implementar uma solução democrática. Os países com experiências prévias com o ensino à distância ou com logística para implementação em tempo recorde ensino mediado por tecnologia, como a China, ofereceram para seus professores e estudantes, ferramentas capazes de manter a continuidade das aulas.

No Brasil, a situação de acesso limitado, tanto à internet quanto aos equipamentos que permitem a interação estudante-professor, alinhada às diversidades sociais e regionais, tornaram o processo extremamente complexo. As aulas passaram a ser ministradas e ou transmitidas pela internet, pela televisão ou pelo rádio. Em algumas escolas, o material foi impresso e entregue ou enviado aos estudantes. Os professores tiveram que adaptar as atividades que desenvolviam no ensino presencial a esta nova realidade. Com tantos e diversificados fatores envolvidos, a pandemia da Covid-19 abriu a ferida das limitações da formação, levando governos, gestores e profissionais da educação a buscarem soluções que expuseram o mar de diferenças sociais e de aprendizagem existentes no país. O fato é que não houve preparação prévia, não foi disponibilizada a infraestrutura mínima necessária para que os professores conseguissem produzir materiais e aulas dignas para os seus estudantes. As alternativas adotadas revelaram muito mais dúvidas do que respostas, mais silêncio e menos aprendizagens. A formação anteriormente dedicada aos professores da educação básica já não era suficiente e uma nova emergiu em meio às necessidades impostas pela pandemia.

Se assim o é de uma forma mais geral, quando são observadas as especificidades de cada uma das áreas de conhecimento da educação básica, as adversidades de desdobram, em especial, para o ensino de Ciências e para a Educação Ambiental, do que 
irá tratar a próxima seção deste artigo.

\section{Ensino de Ciências e Educação Ambiental}

Um aspecto extremamente relevante, que não pode ser negligenciado ao se tratar da pandemia da Covid-19, é o processo de demonização da ciência. Um movimento contra a força das evidências e da pesquisa empírica, que contraria qualquer senso comum, montando um cenário anticiência (HENRIQUES; VASCONCELOS, 2020).

Nesse novo contexto de dúvidas e inseguranças e de manifestações contrárias à ciência, o ensino de Ciências ganha um novo significado e a Educação Ambiental se fortalece como ferramenta de transformação social, principalmente por ser, como diz Loureiro (2004) "complexa, trans e interdisciplinar". Brumati (2011) entende que a Educação Ambiental e o ensino de Ciências, conjugados, podem preparar pessoas mais responsáveis e solidárias, que coletivamente podem colaborar para um planeta mais sustentável. No entendimento de Loureiro (2004):

Educação Ambiental é uma perspectiva que se inscreve e se dinamiza na própria educação, formada nas relações estabelecidas entre as múltiplas tendências pedagógicas e do ambientalismo, que têm no "ambiente" e na "natureza" categorias centrais e identitárias. Neste posicionamento, a adjetivação "ambiental" se justifica tão somente à medida que serve para destacar dimensões "esquecidas" historicamente pelo fazer educativo, no que se refere ao entendimento da vida e da natureza, e para revelar ou denunciar as dicotomias da modernidade capitalista e do paradigma analítico-linear, não dialético, que separa: atividade econômica, ou outra, da totalidade social; sociedade e natureza; mente e corpo; matéria e espírito, razão e emoção etc (LOUREIRO, 2004, p.66)

A formação dos professores de Ciências e de Educação Ambiental, em meio à pandemia da Covid-19, ocupa lugar importante nesse contexto e requer um processo que valorize as potencialidades dos saberes voltados para a sustentabilidade e proteção da vida, alinhados ao uso de tecnologias alternativas para a interação remota entre professores e estudantes. A formação dos professores de Ciências deve, portanto, estar comprometida com a interpretação dos impactos ambientais e ecológicos e as mudanças estruturais causadas pela pandemia na vida do planeta, no sentido em que tais análises permitam a produção de novos conhecimentos que transformem os espaços de aprendizagem. É preciso garantir que o conhecimento e as competências adquiridas por meio da Educação Ambiental se alinhem com um novo olhar sobre as relações homemmeio e o uso de novas tecnologias educacionais. Nesse sentido, soluções importantes para o enfrentamento dos problemas ambientais podem ser criadas, facilitando o processo de ensino e aprendizagem em momentos como o da pandemia.

Assim sendo, é premente debater sobre o papel da Educação Ambiental na construção do "novo" normal, levando em consideração o uso das tecnologias educacionais 
para o ensino remoto, mas também a construção de alternativas de retorno às escolas póspandemia, preparando professores e estudantes para viverem e conviverem de uma outra maneira, em um outro ambiente, modificado pelas limitações que ainda restarão por muitos meses ao fim do isolamento social a que hoje estão submetidos.

De outra forma, não se pode descartar a possibilidade do ensino híbrido, que poderá se constituir como uma alternativa para a retomada segura às atividades escolares, ainda que com o cumprimento de todos os protocolos recomendados pelos gestores e profissionais de saúde. De toda maneira, políticas públicas específicas podem ser pensadas para sanar essa dificuldade, permitindo assim o mais importante, que os estudantes possam exercer o seu direito de aprender com dignidade. Porém, é necessário refletir e reforçar que, por mais que haja uma formação robusta de professores, tendo como referência a realidade escolar, o professor não é e nem deve ser responsabilizado pelas dificuldades que permeiam a educação, como as diferenças sociais, as condições elementares de infraestrutura das escolas. De acordo com Soares (2013), um estudo sobre infraestrutura das escolas revelou que mais de $44 \%$ das escolas da educação básica brasileira ainda apresentavam uma infraestrutura escolar considerada como elementar, ou seja, nível um, em uma escala com quatro níveis. Isto significa que essas escolas tinham apenas água, sanitário, energia, esgoto e cozinha. É nesse cenário de infraestrutura elementar que o professor tem que se desdobrar para garantir minimamente o processo de ensino-aprendizagem. Com tantas incertezas, os desafios são imensos e implicam em uma mobilização dos gestores da educação pública por meio de:

- Fortalecimento da infraestrutura para do ensino online, tendo em vista a possibilidade de realização de disciplinas no contexto híbrido de ensino, limitando o tempo de permanência do estudante em sala de aula.

- Implementação de políticas de conscientização e de cuidados na higiene pessoal no contexto escolar.

- Elaboração de programas específicos para a formação de professores e gestores escolares.

- Instituição mecanismos de acompanhamento dos estudantes, principalmente os mais vulneráveis.

- Aproveitamento dos espaços abertos das escolas (ginásios, pátios, anfiteatros, entre outros), tendo como referência as aprendizagens desenvolvidas no Ensino de Ciências e a oportunidade de adotar, no cotidiano escolar, os saberes aprendidos em Educação Ambiental.

\section{Considerações Finais}

A temática de formação de professores é extensa e deve ser pensada e repensada constantemente, afinal a dinâmica do mundo não nos permite criar moldes rígidos que não admitam criatividade e liberdade aos professores possa exercerem sua profissão. Sendo assim, considerando os marcos regulatórios apresentados a respeito da formação do 
professor, as lacunas existentes quanto à formação em contraposição às aprendizagens alcançadas pelos professores e estudantes de escolas públicas no período da quarentena da pandemia da Covid-19 e a importância do Ensino de Ciências e da Educação Ambiental nesse contexto, torna-se necessário criar cenários prospectivos para o pós-pandemia, que possibilitem estratégias inovadoras, com o objetivo de proporcionar aos estudantes das escolas públicas acesso aos saberes historicamente construídos, aos quais tiveram acesso limitado pelas próprias limitações infraestruturais das escolas e de vulnerabilidade social e econômica a que estão submetidos.

O presente texto, produzido com a finalidade de analisar esse contexto, composto pela formação de professores para o Ensino de Ciências e o papel da Educação Ambiental durante a quarentena do Covid-19 e no retorno às escolas no pós-pandemia da Covid-19, tendo como pano de fundo o uso da tecnologia educacional como possibilidade de uma interlocução transformadora na vida escolar, apenas inicia uma discussão que precisa ser aprofundada a partir de elementos resultantes das experiências vivenciadas por gestores, professores e estudantes durante os seus afastamentos das unidades escolares. Aos pesquisadores, a educação escolar na escola básica, a partir do retorno dos estudantes às escolas, especialmente dos estudantes das escolas públicas, reserva inúmeros objetos de estudo, que deverão ser investigados em momentos posteriores. Por ora, fica-nos a certeza de que a afirmação do Ensino de Ciências como aquele que permite o acesso às alternativas para a vida humana e uma maior atenção em torno das questões ambientais são elementos fundamentais à vida em sociedade.

\section{Referências}

BRASIL, MEC/CNE. Resolução CNE/CP n 2, de 15 de junho de 2012. Estabelece as Diretrizes Curriculares Nacionais para a Educação Ambiental. Disponível em:

http: / / portal.mec.gov.br/index.php?option=com_docman\&view=download\&alias =10988-rcp00212-pdf\&category_slug=maio-2012-pdf\&ltemid=30192 Acesso em: 03/09/2020.

BRASIL, MEC/CNE. Resolução CNE/CP n² 2, de 20 de dezembro de 2019.Define as Diretrizes Curriculares Nacionais para a Formação Inicial de Professores para a Educação Básica e institui a Base Nacional Comum para a Formação Inicial de Professores da Educação Básica (BNC-Formação). Disponível em:

http: / $/$ portal.mec.gov.br/index.php?option=com_docman\&view=download\&alias $=135951$ rcp002-19\&category_slug=dezembro-2019-pdf\&ltemid=30192 Acesso em : 02/09/2020

BRASIL, MEC/CNE.Resolução CNE/CP n 1, de 2 de julho de 2019.Altera o Art. 22 da Resolução $\mathrm{CNE} / \mathrm{CP} \mathrm{n}^{\circ} 2$, de $1^{\circ}$ de julho de 2015, que define as Diretrizes Curriculares Nacionais para a formação inicial em nível superior (cursos de licenciatura, cursos de formação pedagógica para graduados e cursos de segunda licenciatura) e para a formação continuada. Disponível em: http: / portal.mec.gov.br/index.php?option=com_docman\&view=download\&alias $=116731$ rcp001-19\&category_slug=julho-2019-pdf\&Itemid=30192 Acesso em: 02/09/2020

BRASIL, PILab,UnB - Nota técnica Retorno às atividades IFES - 27 de maio de 2020. 
BRASIL. Decreto ${ }^{\circ} \mathbf{8 . 9 7 7}$, de 30 de janeiro de 2017. Aprova o Estatuto e o Quadro Demonstrativo dos Cargos em Comissão e das Funções de Confiança da Coordenação de Aperfeiçoamento de Pessoal de Nível Superior - Capes e substitui cargos em comissão do Grupo-Direção e Assessoramento Superiores - DAS por Funções Comissionadas do Poder Executivo - FCPE. Disponível em: http://www.planalto.gov.br/ccivil_03/_ato2015-2018/2017/decreto/D8977.htm. Acesso em: 12 set. 2020.

BRASIL. Lei n. 9.795 de 27 de abril de 1999. Dispõe sobre a Educação Ambiental, institui a Política Nacional de Educação Ambiental - PNEA e dá outras providências. Disponível em: https://www.planalto.gov.br/ccivil_03/leis/19795.htm Acesso em: 03 set. 2020.

BRASIL. Lei $n^{\circ} 11.502$, de 11 de julho de 2007. Modifica as competências e a estrutura organizacional da fundação Coordenação de Aperfeiçoamento de Pessoal de Nível Superior CAPES, de que trata a Lei no 8.405, de 9 de janeiro de 1992; e altera as Leis nos 8.405 , de 9 de janeiro de 1992, e 11.273, de 6 de fevereiro de 2006, que autoriza a concessão de bolsas de estudo e de pesquisa a participantes de programas de formação inicial e continuada de professores para a educação básica. Disponível em:

http://www.planalto.gov.br/ccivil_03/_Ato2007-2010/2007/Lei/L11502.htm. Acesso em: 11 set. 2020.

BRUMATI, Keli Cristina. A Educação Ambiental no Ensino em Ciência. 2011.38 folhas. Monografia (Especialização em Ensino de Ciências). Universidade Tecnológica Federal do Paraná, Medianeira, 2011. Disponível em:

http://repositorio.roca.utfpr.edu.br/jspui/bitstream/1/2594/1/MD_ENSCIE_2011_1_08.pdf Acesso em: 08 set. 2020.

DAL-FARRA, R. A.; VALDUGA, M. A Educação Ambiental na formação continuada de professores: reflexões a respeito das práticas compartilhadas de construção. Linhas Críticas, v. 18, n. 36, p. 395-415, 2012.

FARIA, J. B.; DINIZ-PEREIRA, J. E. Residência pedagógica: afinal, o que é isso? Revista de Educação Pública, [S. I.], v. 28, n. 68, p. 333-356, 2019. DOI: 10.29286/rep.v28i68.8393. Disponível em: https://periodicoscientificos.ufmt.br/ojs/index.php/educacaopublica/article/view/8393. Acesso em: 13 set. 2020. 32167396

GATTI, Bernardete A. Formação de professores no Brasil: características e problemas. Educ. Soc., Campinas, v. 31, n. 113, p. 1355-1379, dez. 2010. Disponível em $<$ http://www.scielo.br/scielo.php?script=sci_arttext\&pid=S010173302010000400016\&lng =pt\&n $\underline{m=i s o}>$. Acesso em: 07 set. 2020. https://doi.org/10.1590/S0101-73302010000400016.

HENRIQUES, Cláudio Maierovitch Pessanha; VASCONCELOS, Wagner. Crises dentro da crise: respostas, incertezas e desencontros no combate à pandemia da Covid-19 no Brasil. Estud. av., São Paulo, v. 34, n. 99, p. 25-44, ago. 2020. Disponível em $<$ http://www.scielo.br/scielo.php?script=sci_arttext\&pid=S010340142020000200025\&lng=pt\&nrm=iso $>$. Acesso em: 08 set. 2020. Epub 10-Jul-2020. http://dx.doi.org/10.1590/s0103-4014.2020.3499.003.

IPEA. Acesso Domiciliar à Internet e Ensino Remoto Durante a Pandemia. Nota Técnica $\mathbf{n}^{\circ} 88$ de 
agosto de 2020. Disponível em:

https://www.ipea.gov.br/portal/images/stories/PDFs/nota_tecnica/200902_nt_disoc_n_88.pdf.

Acesso em: 03/09/2020.

LOUREIRO, C. F. B. Educação Ambiental Transformadora. In: LAYRARGUES, P. P. (Coord.)

Identidades da Educação Ambiental Brasileira. Brasília: Ministério do Meio Ambiente, 2004.

SILVA NETO, Nathanael da Cruz e; LOPES, Silvana Fernandes; TORRES, Julio Cesar; BRANDÃO,

Carlos da Fonseca. A inserção da Capes na formação de professores da educação básica no Brasil.

EccoS Revista Científica, n.40, p.145. Disponível em:

https://www.redalyc.org/articulo.oa?id=715/71548306010161. Acesso em: 13 set. 2020.

SOARES NETO, J. J.; JESUS, G. R.; KARINO, C. A.; D. F. Andrade. Uma Escala para Medir a Infraestrutura Escolar. Estudos em Avaliação Educacional (Impresso), v. 24, p. 78-99, 2013.

UNESCO. COVID-19 RESPONSE. UNESCO 2020 Disponível em: https://en.unesco.org/covid19. Acesso em: 03/09/2020.

VASCONCELOS, C. Possibilidades para a inserção da educação ambiental na formação docente. Revista Espaço Pedagógico, v. 24, n. 2, 14 dez. 2017.

VILLAS BÔAS, Fernanda Litvin; MARTINS, Leila Chalub; SOARES NETO, Joaquim José. Contribuições da Theory-Driven Evaluation para avaliação do Pibid. Estudos em Avaliação Educacional (IMPRESSO), v. 30, p. 70-102, 2019.

ZANCAN RODRIGUES, L.; PEREIRA, B.; MOHR, A. O Documento "Proposta para Base Nacional Comum da Formação de Professores da Educação Básica" (BNCFP): Dez Razões para Temer e Contestar a BNCFP. Revista Brasileira de Pesquisa em Educação em Ciências, v. 20, n. u, p. 1-39, 24 jan. 2020

\section{Andrea Vieira}

Possui graduação em Ciências Econômicas pela Universidade Federal do Rio Grande do Norte (2000), especialização em Economia do Setor Público (2010) e mestrado em Desenvolvimento, Sociedade e Cooperação Internacional (2019) pela Universidade de Brasília (UnB). Doutoranda do curso de Educação em Ciências Química da Vida na Universidade Federal do Rio Grande do Sul (UFRGS) sua pesquisa concentra-se na formação de professores e processos de Internacionalização. Atualmente é Coordenadora Geral do Portal de Periódicos (Capes). Foi Diretora de Formação Docente e Valorização de Profissionais da Educação na Secretaria de educação Básica do Ministério da Educação (MEC) em 2020. Desde 2008 é Analista em Ciência e Tecnologia da Coordenação de Aperfeiçoamento de Pessoal de Nível Superior (Capes), tendo exercido os cargos de Coordenadora de Candidaturas Internacionais (2012-2014), Coordenadora de Bolsas no Exterior (2014-2018) e Coordenadora Geral de Programas Internacionais (2018-2020). Foi secretária executiva e posteriormente Coordenadora do Grupo de Trabalho do Portal de Periódicos da CAPES (2017 - 2020) responsável por avaliar e subsidiar a aquisição e 
renovação de conteúdo do referido Portal. E-mail: andrea.vieira@capes.gov.br. ORCID: https://orcid.org/0000-0002-3776-2477.

\section{Célia Tanajura}

Possui Licenciatura em Letras Vernáculas pela Universidade Estadual do Sudoeste da Bahia (1986), Mestrado em Educação: História, Política, Sociedade pela Pontifícia Universidade Católica de São Paulo (2001) e Doutorado em Educação pela Universidade Federal da Bahia (2007). Realizou o Pós-Doutorado no Centro de Educação da Universidade Federal de Santa Maria (2018). Atualmente é professora da Universidade do Estado da Bahia, conselheira do Conselho Estadual de Educação da Bahia, Conselheira do Conselho Editorial da Editora da Universidade do Estado da Bahia e membro da Rede de Ensino, Pesquisa e Extensão da Educação Profissional e Tecnológica Pública da Bahia. É lider do Grupo de estudos e pesquisas em Gestão, Trabalho e Educação e Professora do Programa de Pós-Graduação em Gestão e Tecnologias em Educação (Gestec/UNEB). Tem experiência na área de Educação, com ênfase em Educação Profissional, atuando principalmente nos seguintes temas: educação profissional, formação de professores, legislação educacional brasileira, política educacional e gestão escolar. E-mail: celia.tanajura@gmail.com. ORCID: https://orcid.org/0000-0001-9015-2726.

\section{Diogo Souza}

Conclui meu curso de Medicina em 1971, na Universidade Católica de Pelotas. Iniciei, em 1972, minhas atividades como aluno e pesquisador em Bioquímica na UFRGS (Prof. Tuiskon Dick). Em 1976 concluí meu Mestrado na UFRJ (Prof. Leopoldo de Meis) e, em 1980, meu Doutorado na UFRJ (Prof. Iván Izquierdo). Em 1980-1981 fiz meu pós-doutorado (CNPq) na University of London (Prof. Richard Rodnight) e em 1987/1988 fui Professor Visitante do Laboratório de Neurobiologia, Universidad Autónoma de Madrid (Prof. Galo Ramirez). Em 1994/1995 fui Professor Visitante no Laboratório de Bioenergética, Departamento de Bioquímica Médica, UFRJ (Prof. Leopoldo de Meis). Em 1998 fui Visiting Scientist, no Neurology Service, Veterans Affair Medical Center, CA, USA (Prof. Raymond Swanson). Já publiquei mais de 500 artigos científicos em revistas indexadas de circulação internacional, orientei inúmeras Teses de Doutorado, Dissertações de Mestrado, Supervisões de PósDoutorado e dezenas de alunos de Iniciação Científica. Esta atuação envolve basicamente a área de Neurociências, onde atuo longo de toda minha vida científica, trabalhando em injúria cerebral mediada por glutamato e neuroproteção exercida pelo nucleosídeo guanosina, abordando aspectos básicos e clínicos de doenças cerebrais. Mais recentemente, comecei a me envolver com a área de Educação em Ciências, onde orientei várias Teses de Doutorado e Dissertações de Mestrado. Recentemente liderei a criação de um PPG em Educação em Ciências na UFRGS, tendo sido seu primeiro Coordenador. Atualmente, sou revisor de artigos científicos em mais de 30 periódicos internacionais, indexados. E-mail: diogo.bioq@gmail.com. ORCID: https://orcid.org/0000-0002-4322$\underline{0404}$. 